\title{
Introduction to "Sixty Years of Modern Tsunami Science, Volume 1: Lessons and Progress"
}

\author{
Utku KânoĞlu, ${ }^{1}$ Emile A. Okal, ${ }^{2}$ Maria Ana Baptista, ${ }^{3,4}$ and Alexander B. Rabinovich ${ }^{5,6}$
}

\begin{abstract}
Twenty-three papers are included in this PAGEOPH topical issue "Sixty Years of Modern Tsunami Science, Volume I: Lessons and Progress". The papers are grouped into four categories: historical tsunami events, studies on tsunami source models and case studies, tsunami hydrodynamics, and probabilistic tsunami hazard assessment and forecasting. Papers that reflect the current state of tsunami science and research are briefly introduced.
\end{abstract}

Keywords: Tsunami observations, Tsunami modelling, Tsunami forecasting, Tsunami hazard assessment.

\section{Introduction}

It has now been a little over 60 years since the great Chilean earthquake of 22 May 1960, which remains to this day the largest ever recorded. This exceptional event also generated a powerful tsunami that remains one of the most devastating far-field ones in the Pacific Basin. It ushered in several decades of unprecedented progress in Solid Earth Geophysics, which rode on the simultaneous development of the unifying theory of Plate Tectonics, the deployment of standardized instrumentation, and the

1 Department of Engineering Sciences, Middle East Technical University, 06800 Ankara, Turkey. E-mail: kanoglu@ metu.edu.tr

2 Department of Earth and Planetary Sciences, Northwestern University, Evanston, IL 60208, USA. E-mail: e-okal@ northwestern.edu

3 Instituto Superior de Engenharia de Lisboa, Instituto Politécnico de Lisboa, Lisbon, Portugal. E-mail: mavbaptista@ gmail.com

4 Instituto Dom Luiz, Universidade de Lisboa, Lisbon, Portugal.

5 Department of Fisheries and Oceans, Institute of Ocean Sciences, 9860 West Saanich Road, Sidney, BC V8L 4B2, Canada. E-mail: a.b.rabinovich@gmail.com

6 P.P. Shirshov Institute of Oceanology, Russian Academy of Sciences, 36 Nakhimovsky Pr, Moscow 117997, Russia. availability of powerful computers and sophisticated analytical techniques.

In this context, our understanding of both scientific and societal issues associated with tsunamis has also been revolutionized over the past 60 years. The combination of analytical methods, powerful computers and laboratory experiments has allowed the development of theoretical models of tsunami waves on the high seas, and of their interaction with sloping beaches. That phenomenon was recognized as a crucial component of the eventual level of destruction and death wrought by tsunamis, using datasets surveyed after the 1992 Nicaragua event. Such postevent surveys became systematic in the aftermath of subsequent tsunamis, and their concept was extended to the reconstruction of historical events through interviews of elderly witnesses. For even older events, the new discipline of paleo-tsunami studies was developed, using a wide range of techniques in sedimentary geology, to provide insight into the recurrence of major tsunamis over time intervals of up to several thousand years.

Because of its extreme death toll of more than 250,000 , and of our failure to adequately warn distant shores, the 2004 Sumatra-Andaman catastrophe resulted in significant progress towards the mitigation of tsunami hazard, in areas as diverse as the systematic instrumentation of the seafloor, the building of regional warning centers, the education of populations at risk, and the application of modern scientific methods to the development of evacuation procedures. In parallel, statistical methods previously developed for the evaluation of seismological risk were adapted to the case of tsunami hazard.

Finally, the occurrence of events triggered by ancillary phenomena, e.g., landslides or meteorological perturbations, have raised our awareness of the diversity in tsunami sources. 
In this very general framework, the present topical issue entitled "Sixty years of modern tsunami science; Volume I" regroups 23 contributions sampling modern aspects of tsunami science, in the wake of the 29th International Tsunami Symposium, held 8-19 July 2019 in Montréal, Canada, during which it was decided to continue the longstanding tradition of publication of PAGEOPH topical issues reflecting the current state of tsunami research, the last two of which were published as Kânoğlu et al. (2019, 2020).

This topical issue is arranged along four major themes, Historical tsunamis, Source models and case studies, Hydrodynamics, and Probabilistic assessment and forecasting. For all of them, we present a short scientific review of each of the papers included.

\section{Historical Tsunami Events}

This topical issue starts with Rajendran et al.'s (2021) investigation of a probable tsunami on the Konkan coast of Western India corresponding to sea disturbances reported by Portuguese mariners in 1524 CE. Using sedimentary features identified in the village of Kelshi, and dated 1508-1681 CE, the authors propose to associate their deposition with flooding over several hundred $\mathrm{km}$ of shoreline by a tsunami originating from an earthquake in the Makran subduction zone, for which they estimate a moment magnitude $M_{w} \geq 9$, barring the effect of any ancillary source such as a landslide or a meteorological event. In the absence of any such earthquake in the documented historical seismicity of the Makran, their study adds a new element to the still controversial question of the maximum magnitude expectable in that region; it concludes by reaffirming the need to reconstruct the historical recurrence of tsunamis along the Makran coast.

In the second paper, Wronna et al. (2021) examine the case of the earthquake of 11 November 1858 in Setúbal, Portugal, which destroyed a large part of the city, and for which historical records suggest anomalous activity in the mouth of the Sado River, leading to the sinking of a number of boats. The authors combine a large dataset of seismic intensities, as well as flooding reports, to propose a source located at the transition between the diffuse Europe-
Nubia plate boundary and the stable continental Iberic block, and featuring a thrust fault mechanism with a strike of $40^{\circ}$. They suggest a value of $6.8 \pm 0.3$ for the magnitude of the earthquake, slightly down from previously published estimates.

Although infrequent, underwater volcanic eruptions are also known to have generated significant tsunamis, some with destructive potential. In this context, Lipiejko et al. (2021) reanalyze the famous tsunami generated by the 1952 explosion of the underwater Myojinsho volcano in the Bonin Islands, that resulted in the loss of the oceanographic vessel Daigo Kaiyo Maru. They use a tidal record at Hachijo Island, $130 \mathrm{~km}$ away, with a maximum peak-to-peak amplitude of $92 \mathrm{~cm}$, and reconsider the model of Duffy (1992) to study the influence of the source time function. They examine (1) an instantaneous source; (2) an explosion of exponentially decaying intensity; and (3) two time-constrained sources, one with a sharp end, and one which terminates with a cavity at the free surface. This last model achieves a satisfactory fit to the observed record, especially regarding the phase and length of the several wave groups. Their results also suggest that the duration of a volcanic explosion controls a beating behavior, as observed on the tidal gauges.

\section{Tsunami Source Models and Case Studies}

In the first paper of this section, Jiménez et al. (2021) investigate the source of the Camanà, Perù earthquake and tsunami of 23 June $2001\left(M_{w}=8.2\right)$. They use a joint dataset of regional geodetic data and mostly far-field tidal gauge records, to increase the stability of their inversion for the distribution of slip on the fault. One of their conclusions is the apparent lack of strain release in the upper portions of the interplate contact, which could suggest the future occurrence of a large shallow event, of particular tsunamigenic potential.

More than 15 years after its occurrence, the catastrophic Sumatra-Andaman tsunami of 26 December 2004 remains the subject of detailed investigations. In the next paper, Fujii et al. (2021) use a combined worldwide dataset from tidal gauges, ocean-bottom sensors and satellite altimetry in an 
inversion of the detailed slip history of the earthquake rupture, with an algorithm accounting for the effects of seawater compressibility, solid Earth elasticity, and gravitational potential variations. They suggest a rupture totalling $\sim 1400 \mathrm{~km}$, at a velocity of $1.3 \mathrm{~km} / \mathrm{s}$, both longer and slower than previously proposed from seismological modelling.

The next two papers relate to the large 2010 BioBío (or Maule) earthquake and tsunami in Southern Chile $\left(M_{w}=8.8\right)$. While not directly related to tsunami genesis, the study by $\mathrm{Li}$ and Chen (2021a, 2021b) estimates variations in apparent stress and in $b$-value to identify anomalous behavior in background seismicity during the four years preceding the 2010 event. The average apparent stress of the eventual rupture area featured a 2.2-fold increase during that time window, correlated with a concurrent decrease in $b$-value.

Klausner et al. (2021) study a Pacific-wide dataset of signals generated by the 2010 Maule tsunami in the vertical and horizontal components of the geomagnetic field. Using four spatio-temporal methods, they separate contributions emanating from magnetic currents in the ocean and the ionosphere. Their study proposes an integrated analysis framework for the identification of such disturbances.

Another tsunami event affecting the Chilean coast was the Illapel earthquake on 16 September 2015 $\left(M_{w}=8.3\right)$, which is the subject of the next two papers. Paulik et al. (2021) investigate building and infrastructure damage in Coquimbo, Chile, after the Illapel earthquake. They identify a practical flow depth threshold of $2 \mathrm{~m}$ under which damage remains mostly repairable, and observed that secondary hazards (e.g., debris) or cascading can lead to failure of seawalls and stormwater culverts, locally enhancing damage to structures such as roads, pathways and utility poles.

In the next paper, Voronina and Voronin (2021) apply the " $r$-solution" methodology to the 2015 Illapel tsunami, which controls the instability inherently present in the inverse problem of the reconstruction of the initial waveform using singular value decomposition. While previous studies separately analyzed parameters such as the number of singular vectors forming the basis of the solution space or the number of spatial harmonics used in the source representation, the authors' approach is to jointly allow a mutual connection between them, which enhances the stability of the inversion.

In the following paper, Cordrie et al. (2021) investigate the source of the 20 July 2017 BodrumKos earthquake and tsunami in the Aegean Sea. Despite its moderate size $\left(M_{w}=6.6\right)$, this event generated a locally destructive tsunami, whose hazard was enhanced by the extremely short travel times to the shorelines at risk, where the populations were not fully prepared to evacuate upon feeling the shaking. Using field data from available post-event surveys, the authors simulated the tsunami for various models, and were able to identify the North-dipping plane as the focal plane of the normal faulting mechanism.

The next paper, by Cilia et al. (2021), addresses the devastating earthquake $\left(M_{w}=7.5\right)$ and tsunami of 28 September 2018 in the Gulf of Palu, Northwestern Sulawesi, Indonesia, which caused over 4,000 casualties and considerable damage around Palu City. The authors gather the results of many field studies (including their own), compiling detailed measurements of seismic intensities, tsunami runup and liquefaction. They discuss three possible interrelated tsunami sources to explain variations in observed and published tsunami runup heights.

The next paper, by Kulikov and Ivanova (2021), compares the tsunamis generated by the three major Kuril Island earthquakes of 4 October 1994, 15 November 2006, and 13 January 2007, which were recorded over the entire Pacific Ocean. Based on field survey data from the Central Kurils and ocean-bottom pressure records from the North Pacific Basin, simulations using validated and calibrated numerical algorithms are used to study the frontal directivity of the energy flux radiated into the ocean by the three sources.

The last paper of the section, Medina et al. (2021a, 2021b), models tsunamis from potential megathrust earthquakes along the entire South American subduction zone. The authors consider ten regional segments, from Colombia to Southern Chile, and calculate runup (including coastal amplification) for 200 non-uniform stochastic sources in each of them. They identify the most vulnerable locations as Valparaíso, Chile, and Lima, Perù, with runup reaching 20 and $25 \mathrm{~m}$, respectively for the most 
likely scenarios, and possibly up to 33 and $40 \mathrm{~m}$ in worst-case scenarios. They also identify coastal regions with higher vulnerability due to tsunami directivity and coastal amplification.

\section{Tsunami Hydrodynamics}

In the first paper of this section, Okal (2021a) investigates tsunami refraction based on Snell's Law, in situations where the ocean's depth varies rapidly. The author first applies shallow-water numerical simulations and beaming techniques over actual sharp bathymetric features in the Pacific Basin, to document tsunami refraction obeying Snell's Law. He then uses the same technique on records of the 2011 Tohoku tsunami obtained at an array of ocean bottom pressure gauges deployed as part of a passive seismic experiment off the coast of Southern California, and observes Snell refraction despite a poorer velocity contrast, and an extremely irregular bathymetry of the shelf.

In the next paper, Okal (2021b) addresses theoretically the question of the energy radiated into a tsunami by a deformation of the ocean floor. By considering the analytical solution developed by Hammack (1972), he shows that, in addition to its expected dependence on the rise time of the source, the energy of the tsunami is limited by the ratio of water depth to source size. While the classic use of the static deformation to estimate tsunami energy (Kajiura, 1981) has no impact in the case of large earthquake sources, the study provides insight on the theoretical limits of this practice, notably outside the shallow-water approximation.

In an approach conceptually similar to Okal (2021b), Fuentes et al. (2021) obtain $(2-\mathrm{D}+1)$ analytical solutions for tsunami sources with timedependent rupture. In addition, a closed-form solution is obtained in the $(1-D+1)$ case. Including source rise time and rupture velocity affects tsunami amplitudes and produces non-negligible shifts in the arrival times for very slow earthquakes. The authors confirm that amplification can occur when the rupture velocity matches the long-wave tsunami speed.

Hartle et al. (2021) present an exact analytical solution for runup in constantly inclined U-shaped parabolic bays. Their solution, based on Green's functions, is robust and avoids indefinite double integrals. They develop a generalized form of the Carrier-Greenspan transformation in the context of narrow bays.

In the last paper of this section, Tehranirad et al. (2021) focus on changes in seafloor morphology due to tsunami impact. They use a new Boussinesq simulation model for weakly dispersive free-surface waves coupled to a depth-integrated model for sediment concentration and modeling of the change in seabed level. The algorithm is verified and tested against both a laboratory dataset and the morphological changes induced by the 2011 Tohoku tsunami in Crescent City, California.

\section{Probabilistic Tsunami Hazard Assessment and Forecasting}

Probabilistic tsunami hazard assessment (PTHA) has become a popular methodology in tsunami-prone areas, especially in the wake of the 2004 Boxing Day event (González et al., 2009); a recent review of the subject can be found in Behrens et al. (2021). The last section of this topical issue starts with two papers focusing on PTHA.

Liu, Ren, et al. (2021) present a PTHA study for the South China Sea, a zone of high tsunami risk. In contrast with previous studies, they consider both local and regional tsunami sources, the latter located at the Manila Trench. They identify the Fujian Province of Southern China as the zone with the highest tsunami risk, and show that potential sources in the Manila Trench and local ones are dominant along different segments of coastlines, suggesting the need to enact locally defined preferential schemes for tsunami mitigation.

Salah et al. (2021) present a PTHA study for the coast of Iran and Pakistan, given the high potential for seismic activity in the region, and despite its relatively low population density. They account for epistemic source uncertainties by employing event tree and ensemble modeling. In addition, they demonstrate that the contribution of aleatory variability, through a probability density function, is 
critical in order to avoid significantly underestimating hazards, especially in the case of long return periods.

Finally, the last three papers in the topical issue address tsunami forecasting, i.e., the problem of estimating quantitatively the local impact of a tsunami in the short time interval between the seismic source and the arrival of the waves at the shores. Wang et al. (2021) present a comprehensive review of the relevant state of the art, including a discussion of technology ranging from seismology to spatial geodesy and ocean floor instrumentation, and of sophisticated techniques allowing both to optimize the deployment of sensors, and to process the data in real time. In particular, they show how algorithms developed in the past ten years could have resulted in an accurate forecast of the 2011 Tohoku tsunami, in the context of patches of exceptionally high slip on the fault plane.

Liu, Rim, et al.'s (2021) study compares different machine learning approaches for forecasting tsunami amplitudes at a set of targeted receivers. Their case study uses one observation point near the entrance of the Strait of Juan de Fuca and two forecast points in the Salish Sea, one in Discovery Bay and the other in Admiralty Inlet, the waterway leading to southern Puget Sound in Washington State. A travel time of $1-2 \mathrm{~h}$ is expected between the observation point and the densely populated shorelines of the Seattle-Tacoma urban community. Their results show that machine learning models can provide excellent predictions from short duration observations, even when truncated before the first wave peak has reached the observation point, underscoring the relevance of using machine learning in future tsunami forecasting.

Mueller et al. (2021) investigate the effect of nonuniform slip distribution uncertainty for regional and local tsunami forecasts for tsunamis reaching the coasts of New Zealand from the Tonga-Kermadec Subduction Zone. They simulate 1632 non-uniform slip ensembles with an ensemble size of 51 scenarios, for each of eight different source locations and four different moment magnitudes $\left(M_{w}=8.1,8.4,8.7,9.0\right)$. Their results show that the forecast threat levels along the coast of New Zealand can change in a considerable number of target zones, and for all magnitudes and distances, when worst-case scenarios are considered for an ensemble-based threat level assessment.

\section{Conclusion}

The two most destructive recent tsunamis, the Palu and Krakatau events in Indonesia, occurred as the previous PAGEOPH topical issue (Kânoğlu et al., 2020) was still in progress, reaffirming our remark that "progress (in tsunami science), is and will remain a never-ending story" reminiscent of the paradox of Zeno of Elea (Okal, 2015, 2019). While remaining vigilant and respectful of the probable contribution of a certain component of good luck, we take comfort in the fact that since the 2004 Indonesian disaster, and notwithstanding traffic accidents during tsunami evacuation, the worldwide community has suffered only two fatalities in the far field, both of them in flagrant violation of evacuation orders, during the 2011 Tohoku event.

Yet, and despite the substantial developments presented herein across many disciplines of tsunami science and engineering, we are unfortunately still faced with many unanswered questions. Unresolved scientific issues include a precise understanding of seismic parameters most critical in the generation of powerful tsunamis, notably in the context of the socalled "tsunami earthquakes", a concept introduced half a century ago by Kanamori (1972). In addition, from the societal standpoint, we still have to address the obvious failures to save lives in the recent Indonesian tsunamis, which raise questions as to how patterns in regional social dynamics may affect the proficiency of warning systems. We can only form the wish that scientific and governmental interests will not wait until the next mega-tsunami (such as the 2004 Indonesian or 2011 Tohoku disasters) to address, and hopefully progress towards answering, such questions and other challenging issues that might be raised in the future.

Publisher's Note Springer Nature remains neutral with regard to jurisdictional claims in published maps and institutional affiliations. 


\section{REFERENCES}

Behrens, J., Løvholt, F., Jalayer, F., et al. (2021). Probabilistic tsunami hazard and risk analysis-a review of research gaps. Frontiers in Earth Science, 9, 628772. https://doi.org/10.3389/ feart.2021.628772

Cilia, M. G., Mooney, W. D., \& Nugroho, C. (2021). Field insights and analysis of the $2018 M_{w} 7.5$ Palu, Indonesia earthquake, tsunami and landslides. Pure and Applied Geophysics. https:// doi.org/10.1007/s00024-021-02852-6 this issue.

Cordrie, L., Gailler, A., Heinrich, P., Briole, P., \& Ganas, A. (2021). The July 20, $2017 M_{w}=6.6$ Bodrum-Kos earthquake, Southeast Aegean Sea: Contribution of the tsunami modeling to the assessment of the fault parameters. Pure and Applied Geophysics. https://doi.org/10.1007/s00024-021-02766-3 this issue.

Duffy, D. G. (1992). On the generation of oceanic surface waves by underwater volcanic explosions. Journal of Volcanology and Geothermal Research, 50(3), 323-344. https://doi.org/10.1016/ 0377-0273(92)90100-R

Fuentes, M., Uribe, F., Riquelme, S., \& Campos, J. (2021). Analytical model for tsunami propagation including source kinematics. Pure and Applied Geophysics. https://doi.org/10. 1007/s00024-020-02528-7 this issue.

Fujii, Y., Satake, K., Watada, S., \& Ho, T.-C. (2021). Re-examination of slip distribution of the 2004 Sumatra-Andaman earthquake $\left(M_{w} 9.2\right)$ by the inversion of tsunami data using the Green's functions corrected for compressible seawater over the elastic earth. Pure and Applied Geophysics. https://doi.org/10. 1007/s00024-021-02909-6 this issue.

González, F. I., Geist, E. L., Jaffe, B., et al. (2009). Probabilistic tsunami hazard assessment at Seaside, Oregon for near- and farfield seismic sources. Journal of Geophysical Research-Ocean, 114, C11023. https://doi.org/10.1029/2008JC005132.

Hammack, J. L, Jr. (1972). Tsunamis-A model of their generation and propagation, Ph.D. Dissertation (261 p.). Pasadena: California Institute of Technology.

Hartle, H., Rybkin, A., Pelinovsky, E., \& Nicolsky, D. (2021). Robust computations of runup in inclined U- and V-shaped bays. Pure and Applied Geophysics. https://doi.org/10.1007/s00024021-02877-x this issue.

Jiménez, C., Carbonel, C., \& Villegas-Lanza, J. C. (2021). Seismic source of the earthquake of Camana Peru $2001\left(\mathrm{M}_{\mathrm{w}}\right.$ 8.2) from joint inversion of geodetic and tsunami data. Pure and Applied Geophysics. https://doi.org/10.1007/s00024-020-02616-8 this issue.

Kajiura, K. (1981). Tsunami energy in relation to parameters of the earthquake fault model. Bulletin of the Earthquake Research Institute, University of Tokyo, 56, 415-440.

Kanamori, H. (1972). Mechanism of tsunami earthquakes. Physics of the Earth and Planetary Interiors, 6(5), 346-359. https://doi. org/10.1016/0031-9201(72)90058-1

Kânoğlu, U., Tanioka, Y., Okal, E. A., Baptista, M. A., \& Rabinovich, A. B. (2019). Introduction to "Twenty five years of modern tsunami science following the 1992 Nicaragua and Flores Island tsunamis, Volume I." Pure and Applied Geophysics, 176(7), 2757-2769. https://doi.org/10.1007/s00024-01902266-5

Kânoğlu, U., Tanioka, Y., Okal, E. A., Baptista, M. A., \& Rabinovich, A. B. (2020). Introduction to "Twenty five years of modern tsunami science following the 1992 Nicaragua and
Flores Island tsunamis, Volume II." Pure and Applied Geophysics, 177(3), 1183-1191. https://doi.org/10.1007/s00024-02002451-x

Klausner, V., Gimenes, H. M., Cezarini, M. V., et al. (2021). Geomagnetic disturbances during the Maule (2010) tsunami detected by four spatiotemporal methods. Pure and Applied Geophysics. https://doi.org/10.1007/s00024-021-02823-x this issue.

Kulikov, E. A., \& Ivanova, A. A. (2021). Tsunami generation efficiency of the 1994, 2006 and 2007 Kuril Islands earthquakes. Pure and Applied Geophysics. https://doi.org/10.1007/s00024021-02887-9 this issue.

Li, Y., \& Chen, X. (2021a). Variations in apparent stress and b value preceding the $2010 \mathrm{M}_{\mathrm{w}} 8.8$ Bio-Bío, Chile earthquake. Pure and Applied Geophysics. https://doi.org/10.1007/s00024020-02637-3 this issue.

Li, Y., \& Chen, X. (2021b). Correction to: Variations in apparent stress and $\mathrm{b}$ value preceding the $2010 \mathrm{M}_{\mathrm{w}} 8.8$ Bio-Bío, Chile earthquake. Pure and Applied Geophysics, 178, 4289. https://doi. org/10.1007/s00024-021-02863-3.

Lipiejko, N., Whittaker, C. N., Lane, E. M., White, J. D. L., \& Power, W. L. (2021). Tsunami generation by underwater volcanic explosions: Application to the 1952 explosions of Myojinsho Volcano. Pure and Applied Geophysics. https://doi. org/10.1007/s00024-021-02857-1 this issue.

Liu, C. M., Rim, D., Baraldi, R., \& LeVeque, R. (2021). Comparison of machine learning approaches for tsunami forecasting from sparse observations. Pure and Applied Geophysics. https:// doi.org/10.1007/s00024-021-02841-9 this issue.

Liu, Y., Ren, Y., Wen, R., \& Wang, H. (2021). Probabilistic tsunami hazard assessment for the Southeast Coast of China: Consideration of both regional and local potential sources. Pure and Applied Geophysics. https://doi.org/10.1007/s00024-02102878-w this issue.

Medina, M., Riquelme, S., Fuentes, M., \& Campos, J. (2021a). Tsunami modeling in the South American subduction zone inferred from seismic coupling and historical seismicity. Pure and Applied Geophysics. https://doi.org/10.1007/s00024-02102808-w this issue.

Medina, M., Riquelme, S., Fuentes, M., \& Campos, J. (2021b). Correction to: Tsunami modeling in the South American subduction zone inferred from seismic coupling and historical seismicity. Pure and Applied Geophysics. https://doi.org/10. 1007/s00024-021-02871-3 this issue.

Mueller, C., Burbidge, D., \& Power, W. (2021). Regional tsunami forecasting: uncertainties due to non-uniform slip. Pure and Applied Geophysics. https://doi.org/10.1007/s00024-021-028455 this issue.

Okal, E. A. (2015). The quest for wisdom: Lessons from seventeen tsunamis, 2004-2014. Philosophical Transactions of the Royal Society (London) Series A, 373, 201403706. https://doi.org/10. 1098/rsta.2014.0370.

Okal, E. A. (2019). Twenty-five years of progress in the science of "geological" tsunamis following the 1992 Nicaragua and Flores events. Pure and Applied Geophysics, 176(7), 2771-2793. https://doi.org/10.1007/s00024-019-02244-x

Okal, E. A. (2021a). Snell's law applied to tsunamis: Simulations and observations. Pure and Applied Geophysics. https://doi.org/ 10.1007/s00024-021-02703-4 this issue.

Okal, E. A. (2021b). The energy of a tsunami generated by dynamic uplift of the ocean bottom. I. Analytical solutions. Pure 
and Applied Geophysics. https://doi.org/10.1007/s00024-02102804-0 this issue.

Paulik, R., Williams, J. H., Horspool, N., et al. (2021). The 16 September 2015 Illapel earthquake and tsunami: Post-event tsunami inundation, building and infrastructure damage survey in Coquimbo, Chile. Pure and Applied Geophysics,. https://doi.org/ 10.1007/s00024-021-02734-x this issue

Rajendran, C. P., Heidarzadeh, M., Sanwal, J., Karthikeyan, A., \& Rajendran, K. (2021). The orphan tsunami of 1524 on the Konkan coast, western India, and its implications. Pure and Applied Geophysics. https://doi.org/10.1007/s00024-020-025750 this issue.

Salah, P., Sasaki, J., \& Soltanpour, M. (2021). Comprehensive probabilistic tsunami hazard assessment in the Makran subduction zone. Pure and Applied Geophysics. https://doi.org/10.1007/ s00024-021-02725-y this issue.

Tehranirad, B., Kirby, J. T., \& Shi, F. A. (2021). A numerical model for tsunami-induced morphology change. Pure and
Applied Geophysics. https://doi.org/10.1007/s00024-020-02614$\mathrm{w}$ this issue.

Voronina, T. A., \& Voronin, V. V. (2021). A study of implementation features of the $r$-solutions method for the tsunami source recovering in the case of the Illapel tsunami 2015. Pure and Applied Geophysics. https://doi.org/10.1007/s00024-021-028437 this issue.

Wang, Y., Tsushima, H., Satake, K., \& Navarrete, P. (2021). Review on recent progress in near-field tsunami forecasting using offshore tsunami measurements: Source inversion and data assimilation. Pure and Applied Geophysics. https://doi.org/10. 1007/s00024-021-02910-z this issue.

Wronna, M., Baptista, M. A., \& Miranda, J. M. (2021). Reevaluation of the 11 November 1858 earthquake and tsunami in Setúbal-a contribution to the seismic and tsunami hazard assessment in southwest Iberia. Pure and Applied Geophysics. https://doi.org/10.1007/s00024-021-02885-x this issue.

(Published online December 2, 2021) 